\title{
THE INVASIVE NEW ZEALAND MUDSNAIL, POTAMOPYRGUS ANTIPODARUM, REDUCES GROWTH OF THE NATIVE SNAIL, FOSSARIA SP.
}

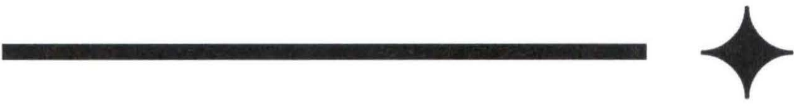 \\ AMY C. KRIST $\downarrow$ DEPARTMENT OF ZOOLOGY AND PhySIOLOGY \\ UNIVERSITY OF WYOMING — LARAMIE \\ MARK F. DYBDAHL + SCHOOL OF BIOLOGICAL STUDIES \\ WASHINGTON STATE UNIVERSITY $\downarrow$ PULLMAN
}

\section{INTRODUCTION}

Invasive species are one of the greatest threats to global biodiversity. Hence, understanding the role of invasive species is of grave importance to managing and minimizing the impact of biological invasions. To date, the ecological impacts of biological invasions have received significant attention, but little effort has been made to address the evolutionary impact (Sakai et al. 2001, Cox 2004). This is despite the fact that evolutionary impacts are likely to be widespread; invasive species have been shown to alter patterns of natural selection or gene flow within native populations (Parker et al. 1999), and many of the best examples of rapid evolution involve invasive species interacting with native species (Reznick and Ghalambor 2001, Strauss et al. 2006). We have begun to address some of the evolutionary consequences of the invasion of the New Zealand mud snail, (Potamopyrgus antipodarum) on a species of native snail in the Greater Yellowstone Area (GYA).

Potamopyrgus antipodarum are a likely selective agent on native snails because they have achieved very high densities in the invasive range $\left(500,000 / \mathrm{m}^{2}\right.$ in some areas of the Greater Yellowstone Ecosystem; Hall et al. 2003) and dominate these communities (Kerans et al. 2005, Hall et al. 2006). These densities translate into a strong impact on the biotic and abiotic environment. For example, Hall and colleagues (2003) showed that $P$. antipodarum consumed $75 \%$ of gross primary productivity, and Riley and colleagues(in review) showed that they reduce periphyton biomass (the microscopic algae, fungi, and bacteria on substrata). Because the growth of individuals and populations of algivores can be limited by the abundance of algae (reviewed in Lamberti 1996), this consumption of the majority of resources by $P$. antipodarum is likely to have a negative effect on other benthic herbivores. Hence, one way $P$. antipodarum may be impacting native snails and other benthic herbivores is by reducing their evolutionary fitness through consumption of resources. These detrimental consequences to the fitness of native invertebrates may either reduce their population sizes or, with sufficient time and genetic variation, lead to evolutionary change in populations of natives.

Indeed, consumption of resources by $P$. antipodarum has been shown to cause exploitative competition with a native snail. In experimental chambers, $P$. antipodarum reduced the growth rate of the native hydrobid Pyrgulopsis robusta in two streams in the GYA (Riley et al. in review). We used two methods to determine whether P.antipodarum are competing with another native snail (Fossaria sp.). First, we sampled every $150 \mathrm{~m}$ along a $900 \mathrm{~m}$ stretch of Polecat Creek to determine whether the 
densities of the two species are correlated. If competition is occurring and reducing their population sizes, the densities of the invasive snail should be negatively correlated with densities of the native snail. Second, we conducted an experiment to determine whether interspecific or intraspecific competition reduces growth and reproduction of the native Fossaria and the non-native $P$. antipodarum. Although P.antipodarum may be competing with native invertebrates for either food or space (Kerans et al. 2005), our experiment only addressed competition for food. We only report on the results of the competition experiment because the data on the relationship between densities of the invasive and the native snail in Polecat Creek are still being collected.

We conducted an experiment to examine growth and reproductive output in interspecific and intraspecific competition treatments at two different densities. To address intraspecific competition, we used experimental chambers with high or low densities of one species. To address interspecific competition, we mixed both species at high or low densities. For each species, we asked whether interactions with conspecifics or the other species had a greater effect on growth and reproduction.

\section{$\downarrow$ METHODS}

\section{Experimental design}

We performed a field experiment in the summer of 2005 in Polecat Creek (Roosevelt National Parkway) to assess the competitive interactions between the invasive P.antipodarum and the native snail Fossaria sp., in terms of on growth and reproduction. For each species, there were two levels of density (low and high) and two types of competition (intraspecific and interspecific). We determined the biomass for the density treatments by measuring the densities of both species in four random samples from the site of the experiment. Low density (1x, $550 \mathrm{mg}$ AFDM/m2) was within the range of ambient density for both species. High density was eight times the ambient density (8x, $4400 \mathrm{mg}$ $\mathrm{AFDM} / \mathrm{m} 2$ ). We varied densities to determine whether competition occurred under current conditions (low density) or only when resources are very limited (high densities). Intraspecific competition was addressed in half of the experimental chambers containing only one species (all Fossaria or all Potamopyrgus). Interspecific competition was addressed in the rest of the chambers containing a mixture of both species.
To examine the impact of competition on the growth of each species, we designated 15 target snails in each experimental chamber. These animals were marked by placing a dab of water-proof paint on their shell. We measured the length of the shell of each target snail at the beginning of the experiment and at the end of the experiment (two weeks later). Since the growth of P.antipodarum decreases markedly after sexual maturity (Jokela and Lively 1995), we selected small snails that were likely to be immature for the target snails of this species. For $P$. antipodarum, the mean size of the target snails was $2.17 \mathrm{~mm}(\min .=1.61 \mathrm{~mm}, \max .=3.02 \mathrm{~mm})$. Likewise, small Fossaria were marked as target snails. These snails were sorted by hand from the random samples that we collected. The mean size of the target Fossaria was $6.54 \mathrm{~mm}$ (min. $=2.59 \mathrm{~mm}$, max. $=7.97 \mathrm{~mm}$ ). Although little is known about the life history of this species, in the congener Fossaria cubensis, size at maturity is between 10 and $12 \mathrm{~mm}$ (Gutierrez et al. 2000).

We controlled for biomass in each experimental chamber by converting the length of the snails to ash free dry mass (AFDM ) using lengthmass regressions for Fossaria (Riley, unpublished) and $P$. antipodarum (Hall, unpublished). Then, we placed equal amounts of AFDM for each density (550 mg AFDM $/ \mathrm{m} 2$ for low density and $4400 \mathrm{mg}$ $\mathrm{AFDM} / \mathrm{m} 2$ for high density) into the experimental chambers. This also serves to control for differences in body size since adult Fossaria are much larger than $P$. antipodarum. For the interspecific competition treatment, the differences in density were achieved by altering the non-target (other) species; the numbers (AFDM) of the target species (target and reproductive snails) were the same for both densities (Table 1).

To examine the impact of competition on the reproduction of each species, we included reproductive snails in addition to the target snails. To match the biomass across experimental chambers of the same density treatment, the AFDM of the target snails was subtracted from the total biomass needed and we then added the appropriate number of reproductive snails to yield the treatment biomass for that species. Hence for the experimental chambers with interspecific competition, there were 15 target individuals of species $\mathrm{A}$, reproductive adults of species A (number varies by density treatment, Table 1 ), and a variable number of snails of species B to equal the total biomass of that density treatment (mg of AFDM for each density given above). Overall, there were 8 treatments, low and high density for intraspecific and interspecific competition for both 
species ( 2 density $\times 2$ competition $\times 2$ species $=8)$, with three replicates per treatment.

\begin{tabular}{llllll}
\hline $\begin{array}{l}\text { Competition } \\
\text { Treatment }\end{array}$ & Density & Target species & $\begin{array}{l}\mathrm{N} \\
\text { target }\end{array}$ & $\begin{array}{l}\mathrm{N} \\
\text { reproductives }\end{array}$ & $\begin{array}{l}\mathrm{N} \\
\text { (other } \\
\text { species) }\end{array}$ \\
\hline Intraspecific & Lo & Fossaria & 15 & 18 & 0 \\
Intraspecific & $\mathrm{Hi}$ & Fossaria & 15 & 80 & 0 \\
Interspecific & Lo & Fossaria & 15 & 9 & 86 \\
Interspecific & Hi & Fossaria & 15 & 9 & 692 \\
Intraspecific & Lo & Potamopyrgus & 15 & 172 & 0 \\
Intraspecific & Hi & Potamopyrgus & 15 & 778 & 0 \\
Interspecific & Lo & Potamopyrgus & 15 & 86 & 16 \\
Interspecific & Hi & Potamopyrgus & 15 & 86 & 127 \\
\hline
\end{tabular}

Table 1. Number of snails placed in each experimental chamber by treatment. Because we controlled for biomass across treatments, the total biomass in each experimental chamber for a given density are equivalent, whether the biomass is composed of a single species (intraspecific competition) or mixed species (interspecific competition). Since the two species of snails differ in size, the numbers of each species vary. $\mathrm{N}$ refers to the sample size of the target snails, the reproductive snails (same species as target snails), and number of snails of the other species.

Experimental cages were constructed from $0.0182 \mathrm{~m}^{2}$ plastic storage containers. We cut out the plastic from each side and from the top and replaced it with $122 \mu \mathrm{m}$ mesh Nytex screen. The screen allowed water to flow through the chambers but kept the egg masses of Fossaria and the newly hatched juveniles of $P$. antipodarum inside.

To assemble the experimental chambers, we attached each plastic chamber to a brick by threading a $14 \mathrm{~cm}$ long bolt through a hole in the bottom of the chamber and attaching nuts and washers to the bottom of the brick to secure the two together. Next, we placed between five and six rocks from the surrounding stream in each experimental chamber. These rocks, which had been cleaned of benthic invertebrates, possess periphyton and provide nutrients for the snails. Snails were added to each chamber according to the appropriate biomass and species combination. Then, we placed the chambers in the stream to a depth that covered the rocks in the chamber but also allowed some air at the top of the cage. The air pocket was required because Fossaria possess lungs and breathe air.

The experiment was set-up on July 1 and 2, 2005. Every two days during the duration of the experiment, we visited the site of the experiment to check the depth of the experimental chambers and to remove detached algae from the mesh. The experimental chambers were removed from the creek on 15 and 16 July; each experimental chamber remained in the creek for 14 days. At the end of the experiment all of the contents of the chambers (snails, egg masses, algae), except the rocks, were rinsed through a $250 \mu \mathrm{m}$ metal sieve and preserved in $70 \%$ ethanol. Each of the rocks were scrubbed for analysis of chlorphyll $a$.

\section{Measurements of resource use}

We also measured use of algal resources by measuring the concentration of chlorophyll $a$ for each rock. In addition to the experimental chambers containing snails, we also had three experimental chambers that had no snails in them. These chambers served as controls to compare the grazing effect among the treatments. The controls also allow us to determine whether one species utilizes the resource more completely and whether resource use was the cause of competition.

We scraped the periphyton off of each rock with toothbrushes and then collected a volume of the slurry on a glass fiber filter (Gelman AE) using vacuum filtration. We calculated chorophyll $a$ concentrations with a $90 \%$ acetone extraction and spectrophotometric analysis of the extract (APHA 1998). We estimated the exposed surface area of each of the rocks using paper tracing. Hence, we will be able to calculate the concentration of chlorophyll $a$ per unit area. These results are not reported here because they are not yet complete.

\section{Statistical analyses}

We omitted one replicate from each treatment because some of the experimental chambers failed (the Nytex mesh did not remain attached on one or more of the "windows"). In these replicates, the number of snails in the chamber was either higher or lower than the starting number (escapees and émigrés). Therefore, we analyzed the remaining two replicates per treatment.

To determine the effect of the experimental conditions on growth, we converted the length measurements to biomass (AFDM) and compared the biomass measurements at the beginning and end of the experiment among groups. We used a two-way ANOVA with biomass (mg of AFDM) as the dependent variable and with the categorical independent variables, density (low or high) and type of competition (intraspecific and interspecific). We did not use repeated measures ANOVA because snails were marked so that they could be distinguished from the reproductive adults, but not marked individually. Therefore, we have biomass measurements for the group at the beginning and at the end of the experiment. 
The rate of reproduction in each chamber was calculated as rate of reproduction $=o /(r-m)$ where $o$ is the total number of offspring (juvenile $P$. antipodarum, and juvenile and egg masses of Fossaria) in each container, $r$ is the total number of reproductive adults, and $m$ is the total number of snails of the target species that died in each container. Since the timing of mortality is unknown, excluding the dead animals may underestimate the number of animals contributing to reproduction. Despite this potential risk, we excluded the dead animals because of high mortality of Fossaria in the high density treatments. Reproductive rates were also analyzed with a two-way ANOVA. Again the categorical, independent variables were density and type of interaction. All statistics were conducted using the $\mathrm{R}$ statistical package (R Development Core Team, 2005)

\section{$\downarrow \quad$ RESUlTS AND DISCUSSION}

\section{Growth}

Both density and type of competition had significant effects on biomass in the native Fossaria sp. (Table 2A). Not surprisingly, Fossaria showed a significantly higher increase in biomass in the low density treatment than in high density (Table 2A, Fig. 1). This result indicates that a high density of individuals lead to decreased growth, probably because of reduced resources. Importantly, Fossaria also gained significantly less biomass in the interspecific competition treatment than in the intraspecific treatment (Table 2, Fig.1). This result indicates that the invasive snail, $P$. antipodarum had a more detrimental effect on Fossaria's growth than conspecifics. A significant interaction term between density and type of competition was caused by a larger gain in biomass in the intraspecific treatments at low density that at high density (Fig. 1).

In contrast to the native Fossaria, only density had a significant effect on biomass in the invasive $P$. antipodarum (Table $2 \mathrm{~B}$ ); there was no effect of type of competition and no significant interaction term. Similar to Fossaria, the gain in biomass was significantly higher in the low density treatment (Table 2B, Fig. 2). Again, this result suggests that in the high density treatment, the presence of many individuals decreased resources which led to decreased growth. Although an accumulation of nitrogenous wastes may also stunt growth, this explanation is unlikely in this experiment because fresh water flowed constantly through the experimental chambers.

\begin{tabular}{|c|c|c|c|c|}
\hline \multicolumn{5}{|l|}{ A. Fossaria } \\
\hline Source & d.f. & M.S. & F value & $\mathrm{P}$ \\
\hline Density & 1 & 30.30 & 14.66 & 0.0002 \\
\hline Competition & 1 & 17.80 & 8.61 & 0.0038 \\
\hline Density * & 1 & 10.99 & 5.32 & 0.0222 \\
\hline $\begin{array}{l}\text { Competition } \\
\text { error }\end{array}$ & 187 & 2.07 & & \\
\hline \multicolumn{5}{|c|}{ B. Potamopyrgus } \\
\hline Source & d.f. & M.S. & $F$ value & $\mathrm{P}$ \\
\hline Density & 1 & 0.0576 & 4.53 & 0.0347 \\
\hline Competition & 1 & 0.0003 & 0.02 & 0.8886 \\
\hline Density * & 1 & 0.0058 & 0.45 & 0.5011 \\
\hline $\begin{array}{l}\text { Competition } \\
\text { error }\end{array}$ & 189 & 0.0127 & & \\
\hline
\end{tabular}

Table 2. The results of a two-way ANOVA of the effects of density (low and high) and type of competition (intraspecific and interspecific) on the AFDM (mg) of the target snails before and after the experiment. Separate analyses were conducted for Fossaria (A.) and Potamopyrgus (B.) Statistically significant effects are bolded.
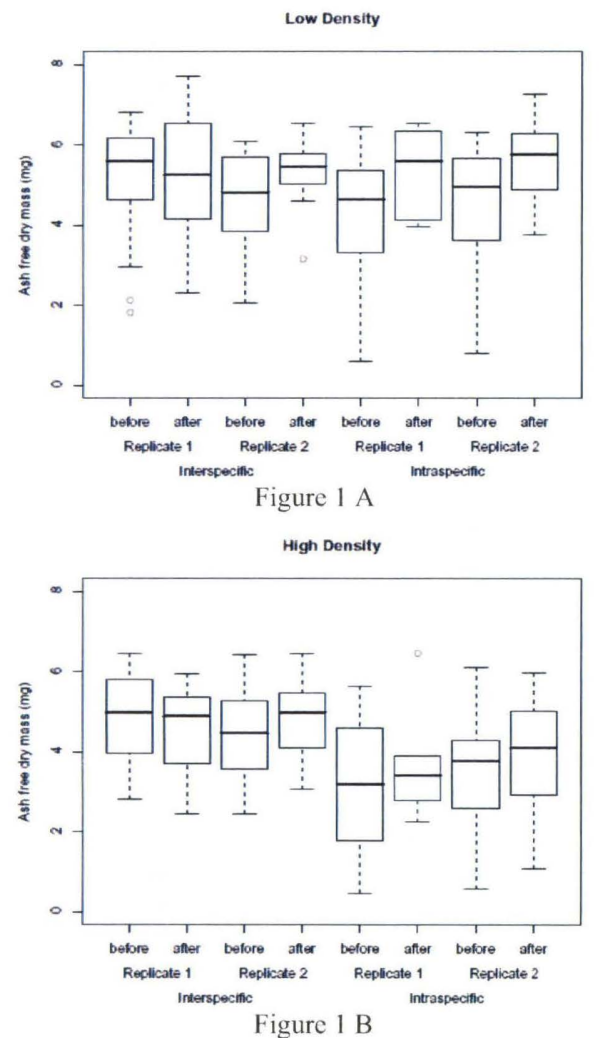

Figure 1. The change in biomass (AFDM in mg) of Fossaria between the beginning of the experiment (before) and two weeks later at the end of the experiment (after), for each replicate for interspecific and intraspecific competition treatments. In these boxplots, the dark, horizontal line is the median, the box bounds the $75^{\text {th }}$ and $25^{\text {th }}$ percentiles, and the whiskers bound the $90^{\text {th }}$ and $10^{\text {th }}$ percentiles. Any outliers are plotted as open circles. The low density treatments are shown in A) and the high density in B).

Despite the fact that conspecifics can have identical resource needs, interspecific interactions had a greater impact on the growth rate of Fossaria than did intraspecific interactions. This result is 
surprising and suggests that $P$. antipodarum may be depressing the periphyton resource to a greater extent than Fossaria. This explanation would also explain why there was no effect of competition type in $P$. antipodarum (intraspecific and interspecific competition treatments had an equivalent effect on growth). We will be able to address this hypothesis with the data on concentrations of chlorophyll $a$.

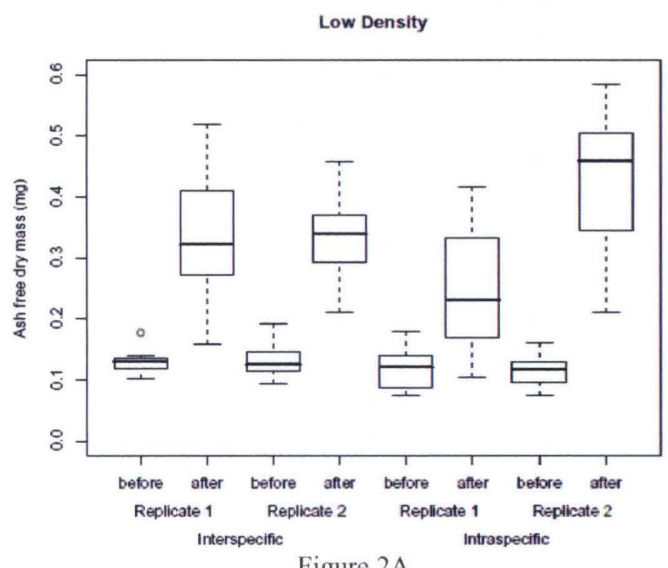

Figure 2A

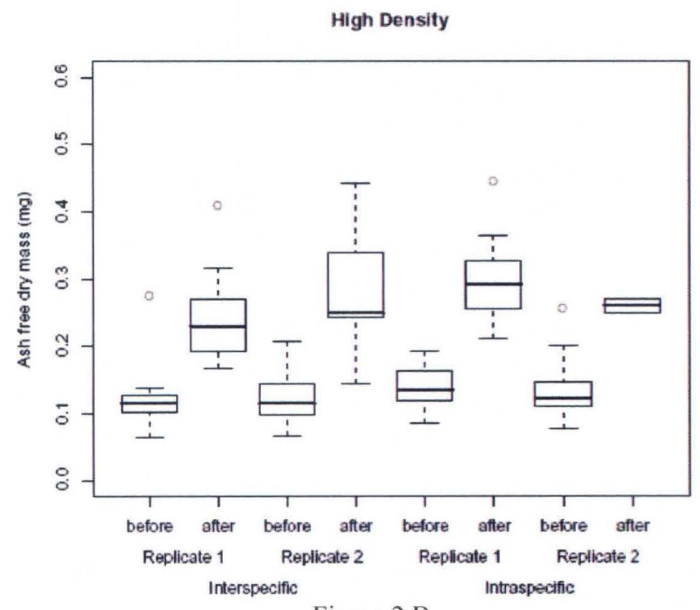

Figure $2 \mathrm{~B}$

Figure 2. The change in biomass (AFDM in mg) of Potamopyrgus antipodarum between the beginning of the experiment (before) and two weeks later at the end of the experiment (after), for each replicate for interspecific and intraspecific competition treatments. In these boxplots, the dark, horizontal line is the median, the box bounds the $75^{\text {th }}$ and $25^{\text {th }}$ percentiles, and the whiskers bound the $90^{\text {th }}$ and $10^{\text {th }}$ percentiles. Any outliers are plotted as open circles. The low density treatments are shown in A) and the high density in B).

\section{Reproduction}

Overall, reproductive rate was less affected than growth. In the native Fossaria, there were no significant effects on reproductive rate by either density or type of competition (Table 3A, Table 4A). These results suggest that allocation to reproduction is prioritized over growth; when environmental conditions were poor (e.g. under competition in high density) growth was compromised but not reproductive rate. Another possible explanation is that fourteen days is not long enough to detect a response in reproduction.

\begin{tabular}{|c|c|c|c|c|}
\hline \multicolumn{5}{|l|}{ A. Fossaria } \\
\hline Density & 1 & 6.42 & 0.92 & 0.3907 \\
\hline Competition & 1 & 24.09 & 3.47 & 0.1361 \\
\hline Density * Competition & 1 & 4.83 & 0.69 & 0.4514 \\
\hline error & 4 & 6.95 & & \\
\hline \multicolumn{5}{|l|}{ B. Potamopyrgus } \\
\hline Source & d.f. & M.S. & F value & $\mathrm{P}$ \\
\hline Density & 1 & 0.765 & 2.41 & 0.1954 \\
\hline Competition & 1 & 0.004 & 0.01 & 0.9180 \\
\hline Density *Competition & 1 & 2.556 & 8.07 & 0.0469 \\
\hline error & 4 & 0.317 & & \\
\hline \multicolumn{5}{|c|}{$\begin{array}{l}\text { Table 3. The results of a two-way ANOVA of the effects o } \\
\text { density (low and high) and type of competition (intraspecific and } \\
\text { interspecific) on the reproductive rate of the target snails. Separate } \\
\text { analyses were conducted for Fossaria (A.) and Potamopyrgus (B.) } \\
\text { Statistically significant effects are bolded. }\end{array}$} \\
\hline
\end{tabular}

Results for the invasive $P$. antipodarum were similar. Reproductive rate of $P$. antipodarum was not affected by either density or type of competition (Table 3B, Table 4B). However, there was a significant interaction between density and competition; in the interspecific competition treatment, reproduction was highest in the high density treatments. In contrast, in the intraspecific competition treatment, reproductive rate was highest in the low density treatments (Table 4B).

\section{CONCLUSIONS}

The two species differed in their responses to the experimental conditions. In Fossaria, growth was negatively affected by density and by $P$. antipodarum but not by conspecifics. Reproduction in this species was not affected at all. In contrast, growth of $P$. antipodarum was only affected by density and there was no difference in growth between the intraspecific and interspecific competition treatments. Similar to Fossaria, reproduction in $P$. antipodarum was not significantly affected by the experimental conditions. These results suggest that $P$. antipodarum is the stronger competitor. This asymmetrical relationship actually suggests that the interaction between the two species might best be described as amensal (Begon et al. 1990). Competition involves two species that have negative effects on each other. Inconsistent with this definition, $P$. antipodarum has a negative effect on Fossaria, but Fossaria does not have a significantly negative effect on $P$. antipodarum. An asymmetrical 
relationship was also found between $P$. antipodarum and $P$. robusta (Riley et al. in review).

Regardless of whether the interspecific interaction is best termed competition or amensalism, in an experimental setting, $P$. antipodarum had a negative effect on the growth of the native snail, Fossaria. The reduction in growth of the native Fossaria can lead to reduced population sizes, eventual population declines and possibly local extirpation. If these demographic consequences are not severe, the decrease in fitness of the native caused by reduced growth might lead to selection. For example, selection might favor traits in Fossaria that reduce the overlap in resource use. With sufficient genetic variation and time, this selection can result in evolutionary change in heritable traits. Alternatively, if competition causes age-specific mortality, it might lead to evolution in life-history traits. The possibility that invasive species can have an evolutionary impact within native communities has often been neglected (Sakai et al. 2001).

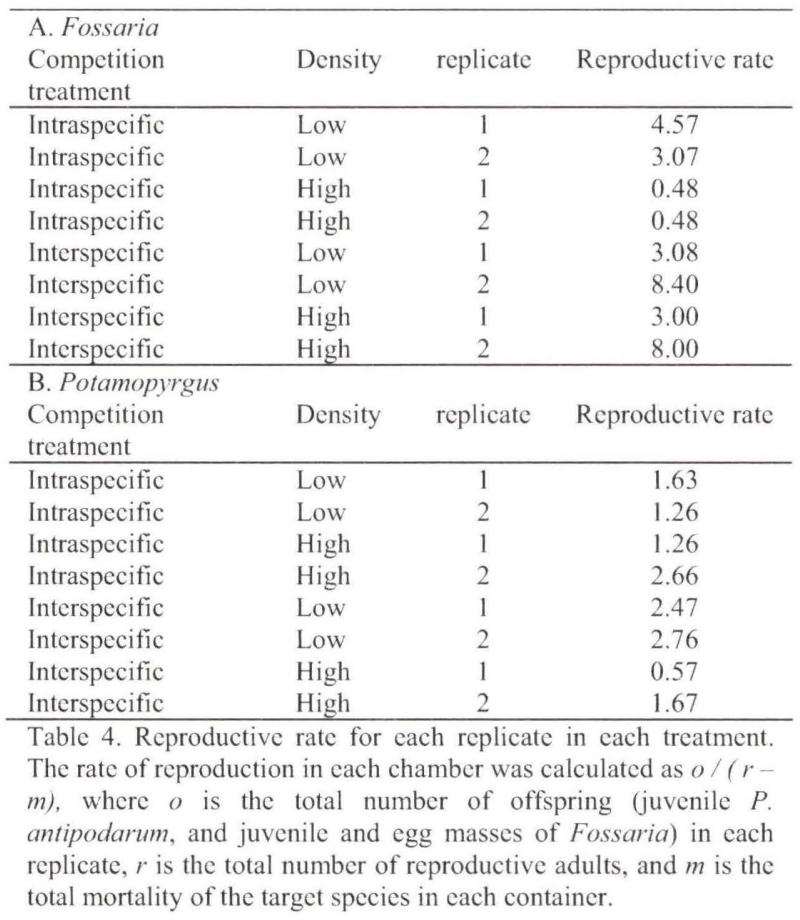

The reduction in growth in the native species most likely resulted from exploitative competition for algal resources. Both of these species consume periphyton and periphyton-covered rocks were the only resource available to the snails in the experimental chambers. The data on chlorophyll $a$ will indicate whether competition occurred over resources.
Whether or not exploitative competition is also occurring in the natural environment depends on whether aquatic algivores are typically limited by the abundance of periphyton. Although we do not have these data, several pieces of evidence suggest that algivores probably are limited by the abundance of periphyton. First, several studies have shown that $P$. antipodarum significantly reduce the biomass of periphyton in experimental conditions (Riley et al. in review, Winterbourn and Fegley, 1989). Second, Kolher and Wiley (1997) showed that population sizes of many aquatic insect taxa were maintained at low levels because of limited periphyton. Third, several studies have suggested that growth of benthic algivores is limited by algal abundance (reviewed by Lamberti 1996). Therefore, while individual streams may vary, it is likely that periphyton is a limiting resource and hence competition over periphyton limits growth and population size of aquatic grazing species.

These results verify that the mud snail invasion should be a concern to biologists and managers. This and other studies (Riley et al. in review) suggest that the mudsnail is having a negative effect on native species. These negative impacts could lead to population declines of natives, local extirpation, or an evolutionary response in the natives. Our results also suggest that density dependent effects on growth and reproduction of P.antipodarum are much smaller than those of the natives (Tables 2 and 3 ). These results suggest that $P$. antipodarum is a superior competitor and further spread of this species is unlikely to be halted by competitive interactions with native organisms.

Studies of severe population declines of a strong grazing competitor in streams, showed the importance of competition in both the composition of aquatic benthic communities and the population dynamics of individual species in the communities (Kohler and Wiley 1997). Hence, the strong competitive interactions by $P$. antipodarum in this study, suggest that they too could change the composition of stream communities and population sizes of species in the communities. In addition, reduced fitness in the native snail in the presence of mudsnails also makes evolutionary change in the native species possible. Hence, the impact of the mudsnail on native communities and species is likely to be widespread and detrimental.

\section{Literature Cited}


APHA (American Public Health Association).1998. Standard methods for the examination of water and wastewater. American Public Health Association, American Water Works Association, and Water Pollution Control Federation, Washington, D.C., USA.

Begon, M., J.L.Harper, and C.R.Townsend, 1990. Ecology: Individuals, Populations, Communities, $2^{\text {nd }}$ edition. Blackwell Scientific Publications, Cambridge, U.S.A.

Cox, G.W. 2004. Alien Species and Evolution: The evolutionary ecology of exotic plants, animals, microbes, and interacting native species. Island Press, Washington, D.C., USA.

Gutierrez, A.G. Perara, M.Yong, J. Sanchez, L. Wong. 2000. Life-history traits of Fossaria cubensis (Gastropoda: Lymnaeidae) under experimental exposure to Fasciola hepatica (Trematoda: Digenea). Mem Inst Oswaldo Cruz, Rio de Janeiro 95: 747-752.

Hall, R.O. Jr., J.L. Tank, M.F. Dybdahl. 2003. Exotic snails dominate nitrogen and carbon cycling in a highly productive stream. Frontiers in Ecology and the Environment. 1:407-411.

Hall, R.O., M.F. Dybdahl, and M.C. VanderLoop. 2006. Invasive species and energy flow: Extremely high secondary production of introduced snails in rivers. Ecological Applications. In Press

Jokela, J. and C.M. Lively. 1995. Parasites, sex, and early reproduction in a mixed population of freshwater snails. Evolution 49: 1268-1271.

Kerans, B.L., M.F. Dybdahl, M.M. Gangloff, and J.E. Jannot. 2005. Potamopyrgus antipodarum: distribution, density, and effects on native macroinvertebrate assemblages in the Greater Yellowstone Ecosystem. J.N. Am. Benthol. Soc. 24:123-138.

Kohler, S.L. and M.J. Wiley. 1997. Pathogen outbreaks reveal large-scale effects of competition in stream communities. Ecology 78:2164-2176.
Lamberti, G.A. 1996. The role of periphyton in benthic food webs. In Algal Ecology: Freshwater Benthic Ecosystems (Stevenson, R.J., Bothwell, M.L. and Lowe, R.L. eds). Academic Press, San Diego, USA.

Parker, I.M., D. Simberloff, W.M. Lonsdale, K. Goodell, M. Wonham, P.M. Kareiva, M.H. Williamson, B. Von Holle, P.B. Moye, J.E. Byers, and L. Goldwasser. 1999. Impact: toward a framework for understanding the ecological effects of invaders. Biological Invasions 1:3-19.

R Development Core Team. 2005. R: A language and environment for statistical computing. $\mathrm{R}$ Foundation for Statistical Computing, Vienna, Austria. ISBN 3-900051-07-0, URL http://www.R-project.org

Reznick, D.N. and C.K. Ghalambor. 2001. The population ecology of contemporary adaptations: what empirical studies reveal about the conditions that promote adaptive evolution. Genetica 112-113:183-198.

Riley, L.A., M.F. Dybdahl, R.O Hall, Jr. in review. Grazing and competition interaction strengths match patterns of introduced species dominance. Biological Invasions.

Sakai, A.K., F.W. Allendorf, J.S. Holt, D.M. Lodge, J. Molofsky, K.A. With, S. Baughman, R.J. Cabin, J.E. Cohen, N.C. Ellstrand, D.E. McCauley, P. O'Neil, I.M. Parker, J.N. Thompson, S.G. Weller. 2001. The Population Biology of Invasive Species. Annu. Rev. Ecol. Syst. 32:305-32.

Strauss, S.Y., J.A. Lau, and S.P. Carroll. 2006. Evolutionary responses of natives to introduced species: what do introductions tell us about natural communities? Ecology Letters 9:357-374.

Winterbourn, M.J. and A. Fegley. 1989. Effects of nutrient enrichment and grazing on periphyton assemblages in some spring-fed, south island streams. New Zealand Natural Sciences 16:57-65 